\title{
POR UMA POLÍTICA DE METAS DE REDUÇÃO DA POBREZA
}

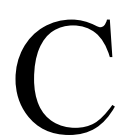
rescimento com distribuição é o maior desafio a ser enfrentado por nós, brasileiros. Por muito tempo os economistas acreditaram que o crescimento da renda per capita de um país era o objetivo maior de uma política econômica. Afinal, crescimento da renda per capita implica maiores recursos econômicos potencialmente capazes de melhorar as condições de vida de todos. Sem negar a importância fundamental do crescimento econômico como motor da melhoria das condições econômicas de todos, sabemos que o usufruto dos benefícios do crescimento não é igualmente compartilhado. A sua distribuição depende de fatores econômicos, sociais e institucionais que variam no espaço e no tempo.

A rigor, a relação entre crescimento e distribuição é uma via de mão dupla, ou seja, crescimento afeta distribuição e distribuição afeta crescimento (FIELDS, 2001). Desde Kuznets (1955) argumenta-se que o início de um processo de crescimento está associado a um aumento da desigualdade. Somente quando o nível de renda per capita de uma economia ultrapassasse um determinado nível, a desi- gualdade começaria a diminuir, ou seja, renda per capita e desigualdade teriam uma relação do tipo U-invertido. Para isso, Kuznets tinha em mente sociedades que transitavam das atividades rurais para as industriais. Inicialmente, algumas pessoas se beneficiariam mais do que outras dos frutos da industrialização, até o momento em que ela fosse predominante na sociedade e a maioria pudesse se beneficiar dos seus resultados.

Mais recentemente, graças aos novos bancos de dados disponíveis e ao avanço tecnológico dos computadores, estudos empíricos mostram que essa relação não é uma lei de ferro e sim uma hipótese não corroborada pelas evidências. Por exemplo, Deininger e Squire (1998), utilizando uma amostra de 48 países, demonstram que não existe uma regularidade entre crescimento e desigualdade ao longo do tempo. Em alguns países a relação é positiva, em outros é negativa e em alguns a correlação é nula. Exemplos paradigmáticos são Brasil entre os anos 1940 e 1980 e Coréia do Sul entre os anos 1960 e 2000, os quais experimentaram crescimento vertiginoso em suas rendas per 
capita nos respectivos períodos, mas enquanto a distribuição de renda se tornava mais desigual no Brasil, na Coréia do Sul ela se tornava mais igualitária. Entender as razões dessa diferença não é tarefa fácil, mas certamente envolve diversos fatores que englobam desde as opções por modelos distintos de crescimento (autarquia e economia aberta) até a adoção de políticas públicas de acesso à educação e saúde.

Em contrapartida, a distribuição de renda também condiciona o crescimento econômico. Embora não haja evidências de uma relação sistemática entre desigualdade e nível de renda, estudos recentes demonstram existir uma relação inversa entre nível inicial de desigualdade e crescimento subseqüente da renda per capita. Os resultados de Clarke (1996), Forbes (1998) e Li e Zou (1998), entre outros, demonstram que maiores níveis de desigualdade inicial de renda afetam negativamente o crescimento econômico dos países. Birsall e Lodoño (1997) concluem que uma maior desigualdade da distribuição do capital humano está associada a um menor crescimento futuro e Deininger e Squire (1998) estabelecem que uma maior desigualdade na distribuição de terras reduz o crescimento subseqüente dos países.

Os mecanismos de transmissão que explicam esses resultados empíricos podem ser os mais variados possíveis. Por exemplo, o trabalho de Kaldor (1956) já enfatizava o papel das maiores propensões a poupar dos mais ricos, revelando assim o dilema entre crescimento e distribuição. Outros autores enfatizam o papel da instabilidade política e macroeconômica da desigualdade, o comportamento rentseeking da elite, a capacidade dos mais ricos para obter poder político e manter seus privilégios, etc. como fatores prejudiciais ao crescimento (ACEMOGLU et al., 2001; PERSSON; TABELLINI, 1994).

Assim, a busca do crescimento com distribuição parece não ter fórmula certa. Ela é um processo aberto no qual o debate democrático sobre as possíveis escolhas de políticas é instrumental ao próprio processo (SEN, 2000). Tendo isso em mente, este artigo é uma contribuição ao debate e aqui sugere-se a introdução de metas explícitas de redução de pobreza na implementação de políticas públicas e sua constante avaliação.

Antes de detalhar o que se entende por metas de redução de pobreza, a primeira parte deste artigo discute as diferentes definições de pobreza e a sua dimensão no Brasil; a segunda parte traz os princípios para a formulação de metas de redução de pobreza e a última parte apresenta algumas considerações finais.

\section{POBREZA NO BRASIL: DEFINIÇÕES E MEDIDAS}

\section{Pobreza como um Fenômeno Multidimensional}

A pobreza é um fenômeno multidimensional. Antes vista apenas como carência de renda, a noção de pobreza e desenvolvimento tem se ampliado consideravelmente no pensamento econômico recente (MEIER; STIGLITZ, 2001). Em uma perspectiva mais abrangente, pobreza pode ser definida como privação de capacidades (SEN, 1981; 1984). De acordo com Amartyia Sen, capacidades significam liberdades substantivas que permitem que as pessoas vivam uma vida que elas possam valorar. A privação de capacidades envolve uma série de restrições que não permitem que as pessoas levem um tipo de vida por elas almejada. Essas restrições podem significar não ter renda monetária suficiente para obter bens e serviços desejados, não ter capacidade física para desenvolver certas atividades, não ter acesso à educação e saúde, não ter livre acesso à troca de bens e serviços, não ter direitos civis e políticos respeitados, etc.

Vista sob o ângulo de privação de capacidades, a pobreza passa a envolver múltiplas dimensões além da simples carência de renda monetária. De fato, caracterizar a pobreza como privação de capacidades tem a vantagem de concentrar a atenção naquilo que é intrinsecamente importante - a expansão das liberdades reais das pessoas - e não apenas num único aspecto que, embora importante, é apenas instrumentalmente relevante.

Essa definição tem importantes conseqüências para políticas públicas, pois dependendo de como se defina o que seja pobreza, indicadores sociais são criados e usados como parâmetros na elaboração e avaliação de políticas.

Para efeitos práticos, países e organismos internacionais elaboram diversos indicadores que são apresentados separadamente ou reduzidos a um único indicador como o Índice de Desenvolvimento Humano das Nações Unidas. A escolha dos indicadores a serem usados e como elaborá-los envolve uma série de opções normativas e metodológicas que devem ser explicitadas.

\section{Indicadores de Pobreza como Insuficiência de Renda}

O uso de indicadores sociais faz sentido quando estes são reconhecidos pelos cidadãos como elementos que representam importantes valores coletivos e intersubjetivos. Por exemplo, as taxas de crescimento do PIB ou as taxas de desemprego tentam inferir aquilo que boa parcela da socie- 
dade julga ser dimensões importante para o país, a saber, crescimento e emprego. Mesmo esses indicadores, já bastante internalizados pelas pessoas, envolvem uma série de opções metodológicas não totalmente conhecidas pelo cidadão comum.

A construção de indicadores de pobreza não envolve menos complexidade. Vejamos o caso da insuficiência de renda. A construção dos indicadores é feita em diversas etapas, sendo que em cada uma se assumem hipóteses específicas. Em geral, o investigador deve considerar:

- a unidade de análise relevante (indivíduos ou famílias);

- o espaço de análise (consumo ou renda);

- a estimação da linha de pobreza;

- a forma de agregação;

- comparações regionais e temporais.

A escolha entre o indivíduo ou a família como unidade de análise depende do objetivo que se tem em mente. Em geral, a meta é ter uma medida homogênea do nível de consumo dos indivíduos para efeitos de comparação temporal ou espacial. Porém, como o consumo de uma pessoa depende da estrutura daquele de sua família que, por seu turno, depende da renda total familiar, a família é tomada como unidade de consumo e renda. As necessidades de consumo de cada membro de uma família variam de acordo com a sua idade, gênero, atividade, etc. Para se estimar o consumo individual, duas opções podem ser consideradas: ou se negligenciam essas diferenças e calcula-se um consumo familiar per capita, ou se estabelece algum critério de adulto-equivalência. Assim, a cada membro da família associa-se um valor de consumo ou renda.

A estimação da linha de pobreza depende do objetivo de obtenção de um indicador de pobreza relativa ou absoluta. O primeiro refere-se à posição da família ou indivíduo em relação ao conjunto da sociedade. Por exemplo, uma linha de pobreza relativa pode ser o valor que corresponda a um quarto da mediana da distribuição da renda per capita familiar de um dado país. As famílias ou os indivíduos com renda inferior àquele número seriam considerados pobres. Já a linha de pobreza absoluta equivale a um valor fixo, que independe de sua posição na distribuição de renda. A vantagem de medir a pobreza relativa é levar em conta aspectos distributivos que os indivíduos possam valorar e a desvantagem é que ela muda toda vez que a distribuição de renda muda e assim não se pode distinguir se uma variação na pobreza decorre da mudança do nível de renda das pessoas ou famílias ou da mudança do valor de referência.
Em compensação, a vantagem de medir a pobreza de forma absoluta é exatamente poder comparar de forma clara níveis de pobreza ao longo do tempo, e entre regiões ou grupos sociais. Neste caso, são necessárias estimativas a partir do valor de cestas de bens de consumo. Apura-se a linha de pobreza em duas partes; de um lado se estabelece o valor da cesta de consumo de bens alimentares e de outro, o valor da de bens não-alimentares. A composição da cesta alimentar deve garantir que certas exigências nutricionais sejam satisfeitas em termos de ingestão calórica e protéica. A seleção dos bens que compõem esta cesta é feita a partir da estrutura de consumo observada naquelas famílias nas quais a renda é suficiente para atender às necessidades nutricionais. Com base no preço desses bens, estabelece-se o valor mínimo da cesta. No caso do Brasil, em 2004, o IBGE divulgou a Pesquisa de Orçamentos Familiares - POF 2002-2003, a qual pela primeira vez teve cobertura nacional. Antes, os estudos faziam uso das POFs de 1987-88 e 1996, cuja abrangência restringiase às regiões metropolitanas e permitia conhecer a estrutura de consumo familiar dessas localidades. Com base nos preços pesquisados pelo IBGE, constrói-se o valor da cesta de bens alimentares, que pode variar entre as regiões por incluir diferentes bens ou diferentes preços. O valor mínimo da cesta alimentar é então denominado linha de indigência.

$\mathrm{O}$ valor da cesta de bens não-alimentares envolve maior arbitrariedade, porque é difícil ter um critério claro de escolha dos bens que a compõem. Uma opção comum na literatura especializada é o uso do coeficiente de Engel (RAVALLION, 1994), que estabelece uma relação entre o consumo alimentar e o consumo total das famílias. $\mathrm{Na}$ prática, ele é obtido da seguinte maneira:

- observam-se os gastos com alimentos e consumo total das famílias;

- dada a linha de indigência, encontram-se as famílias com gastos em consumo total igual ao valor da linha de indigência; - calcula-se a relação entre os gastos alimentares e os gastos totais dessas famílias.

Embora pareça $a d h o c$, a racionalidade desse procedimento reside na hipótese de que essas famílias, mesmo podendo comprar exatamente a cesta alimentar, decidem comprar menos alimentos e mais bens não-alimentares por considerarem estes importantes. Como alternativa, poderse-ia observar o consumo não-alimentar daquelas famílias que gastam em bens alimentares exatamente o valor da linha de indigência. Se por um lado a primeira alternativa 
parece subestimar a linha de pobreza, esta segunda alternativa parece superestimá-la. Qualquer que seja a escolha, o valor da linha de pobreza é o da linha de indigência mais o valor da cesta de bens não-alimentares.

No Brasil, onde existe uma variedade regional de estrutura de consumo e os preços dos bens parecem diferir entre regiões, a depender do objetivo de política que se tenha em mente, torna-se necessário o cálculo de linhas de pobreza regionalizadas. Uma vez estabelecidas as linhas de indigência e pobreza para o Brasil ou para diferentes regiões do país, obtêm-se informações da renda das famílias por meio das pesquisas nacionais ou regionais por amostragem de domicílio. Aqueles indivíduos com rendas familiares per capita ou adulto-equivalente inferiores ao valor da linha de indigência (pobreza) são considerados indigentes (pobres).

\section{Pobreza como Insuficiência de Renda}

Felizmente o debate acadêmico tem aperfeiçoado a elaboração de indicadores de pobreza como insuficiência de renda no Brasil e aprofundado as discussões sobre políticas públicas de combate à pobreza. $\mathrm{O}$ trabalho original de Fava (1984) e os mais recentes de Neri et al. (2003), Rocha (1997, 2003), entre outros, estabelecem com muita solidez os indicadores de pobreza como insuficiência de renda. Como começo está muito bom, pois a renda é uma dimensão instrumental significativa e está fortemente

TABELA 1

Indigência e Pobreza nos Domicílios Urbanos e Rurais

Brasil - 2000

\begin{tabular}{|c|c|c|c|c|c|c|}
\hline \multirow{2}{*}{$\begin{array}{l}\text { Unidades da } \\
\text { Federação }\end{array}$} & \multicolumn{3}{|c|}{ Indigentes } & \multicolumn{3}{|c|}{ Pobres } \\
\hline & Urbano & Rural & Total & Urbano & Rural & Total \\
\hline Brasil & 8,63 & 15,72 & 10,23 & 28,47 & 36,38 & 30,25 \\
\hline Rondônia & 7,47 & 10,92 & 8,93 & 21,43 & 20,50 & 21,04 \\
\hline Acre & 12,26 & 19,15 & 14,74 & 30,15 & 34,22 & 31,62 \\
\hline Amazonas & 16,68 & 32,80 & 20,68 & 35,89 & 53,54 & 40,27 \\
\hline Roraima & 9,19 & 28,69 & 14,88 & 23,67 & 40,10 & 28,47 \\
\hline Pará & 14,31 & 17,42 & 15,38 & 37,00 & 35,96 & 36,65 \\
\hline Amapá & 14,72 & 18,34 & 15,22 & 33,13 & 32,26 & 33,02 \\
\hline Tocantins & 15,73 & 21,79 & 17,62 & 37,42 & 34,98 & 36,65 \\
\hline Maranhão & 17,77 & 30,63 & 23,26 & 45,13 & 60,62 & 51,74 \\
\hline Piauí & 17,33 & 28,78 & 22,10 & 48,62 & 56,48 & 51,89 \\
\hline Ceará & 16,15 & 29,15 & 20,23 & 45,70 & 56,24 & 49,01 \\
\hline Rio Grande do Norte & 11,75 & 23,83 & 15,45 & 31,70 & 48,17 & 36,75 \\
\hline Paraíba & 15,28 & 23,34 & 18,00 & 44,88 & 50,53 & 46,78 \\
\hline Pernambuco & 16,87 & 23,88 & 18,72 & 47,20 & 51,51 & 48,34 \\
\hline Alagoas & 12,39 & 28,57 & 17,91 & 29,98 & 58,84 & 39,82 \\
\hline Sergipe & 14,09 & 20,06 & 16,12 & 41,75 & 50,15 & 44,60 \\
\hline Bahia & 16,37 & 21,64 & 18,26 & 46,53 & 48,91 & 47,39 \\
\hline Minas Gerais & 5,56 & 9,41 & 6,48 & 25,73 & 27,18 & 26,08 \\
\hline Espírito Santo & 5,80 & 4,62 & 5,51 & 26,78 & 20,59 & 25,26 \\
\hline Rio de Janeiro & 8,65 & 5,23 & 8,47 & 27,68 & 26,69 & 27,63 \\
\hline São Paulo & 5,85 & 5,66 & 5,83 & 21,20 & 17,95 & 20,89 \\
\hline Paraná & 5,29 & 9,08 & 6,20 & 20,18 & 26,78 & 21,77 \\
\hline Santa Catarina & 2,89 & 4,98 & 3,50 & 10,02 & 15,38 & 11,59 \\
\hline Rio Grande do Sul & 4,62 & 5,80 & 4,91 & 14,40 & 17,91 & 15,26 \\
\hline Mato Grosso do Sul & 5,49 & 6,60 & 5,72 & 32,99 & 26,95 & 31,71 \\
\hline Mato Grosso & 5,40 & 10,87 & 6,75 & 30,88 & 30,30 & 30,74 \\
\hline Goiás & 5,77 & 7,07 & 6,00 & 36,53 & 26,77 & 34,77 \\
\hline Distrito Federal & 5,15 & 3,96 & 5,07 & 27,03 & 17,31 & 26,37 \\
\hline
\end{tabular}

Fonte: Azzoni, Souza e Nogueira (2004). 
correlacionada a outras também importantes como educação e saúde.

Azzoni, Souza e Nogueira (2004) estimam os indicadores de indigência e pobreza entre os domicílios brasileiros utilizando os microdados do Censo 2000 do IBGE. A vantagem desses dados é permitir calcular indigência e pobreza para todas as regiões do Brasil. A Tabela 1 apresenta os indicadores calculados por esses autores para o Brasil e os Estados da Federação a partir da renda per capita domiciliar, utilizando as linhas regionalizadas de indigência e pobreza de Rocha (1997).

Em todo o Brasil estima-se que cerca de $10 \%$ dos domicílios vivem em condições de indigência e cerca de $30 \%$ deles são pobres. Além disso, a indigência e a pobreza variam consideravelmente entre as regiões urbanas e rurais e entre os Estados. Como se observa na primeira linha da Tabela 1, do total de domicílios em áreas urbanas, 8,63\% são indigentes e $28,47 \%$ pobres, enquanto do total de domicílios em áreas rurais, 15,72\% são indigentes e 36,38\% pobres. Ou seja, em termos proporcionais, as incidências da indigência e da pobreza é maior nas áreas rurais. ${ }^{1}$ Também se observa que a indigência e a pobreza variam consideravelmente entre os Estados. Os Estados das regiões Norte e Nordeste apresentam maiores incidências de indigência e pobreza em relação aos do Sul e Sudeste. Maranhão e Piauí exibem a maior proporção de domicílios pobres (cerca de 52\% cada) e Santa Catarina e Rio Grande do Sul, as menores incidências de pobreza (12\% e 15\%, respectivamente). Por fim, a indigência e a pobreza são diferentes entre as áreas urbanas e rurais dentro de cada Estado e tal relação varia entre os Estados, ou seja, enquanto a indigência e a pobreza são proporcionalmente maiores nas áreas rurais do Norte e Nordeste em relação às suas áreas urbanas, são proporcionalmente maiores nas áreas urbanas dos Estados do Sul e Sudeste em relação às suas respectivas áreas rurais.

Azzoni, Souza e Nogueira (2004) demonstram que as diferenças das incidências da indigência e da pobreza entre os Estados brasileiros e, dentro destes, entre as regiões urbanas e rurais se devem a fatores demográficos e regionais. De um lado essas variações são resultado das diferentes características demográficas e educacionais entre os grupos de domicílios nas diversas regiões. As regiões mais pobres são assim pelo fato de os membros das famílias que aí vivem terem em geral menores níveis de escolaridade. Com efeito, estima-se que, do total da diferença entre as pobrezas do Brasil urbano e rural, 51\% referem-se ao nível de escolaridade dos membros das famílias.
Por outro lado, mesmo depois de considerar as diferenças demográficas e educacionais, ainda assim persiste uma diferença entre os níveis de indigência (e pobreza) entre as diversas regiões do país. Em outras palavras, mesmo após descontar os efeitos das características demográficas e educacionais, a diferenciação regional tem um relevante papel em explicar a heterogeneidade regional da indigência (e pobreza) brasileira.

\section{O Trabalho Infantil}

Outra dimensão importante da pobreza é o trabalho infantil como a privação do pleno desenvolvimento das potencialidades de crianças e adolescentes. Com efeito, ele tem como conseqüência o prejuízo ou mau aproveitamento na formação educacional. Souza (2003) mostra que aqueles indivíduos que trabalharam quando crianças apresentam em média rendimento inferior do trabalho, comparados com aqueles que começaram a trabalhar depois de adultos. Em parte isso se deve à menor educação acumulada. Contudo, mesmo quando se comparam adultos de mesmo nível educacional, ter sido trabalhador infantil afeta negativamente a renda. Isso sugere que o impacto vai além da simples redução do grau de escolaridade.

Em geral, o trabalho infantil está associado às limitadas condições socioeconômicas das famílias. Premidas pelas necessidades mais imediatas, as famílias recorrem a ele como expediente de sobrevivência ou como uso do tempo das crianças e adolescentes por falta de melhores oportunidades ou mesmo por normas sociais locais. Todavia, dentro deste grande guarda-chuva chamado pobreza, existem heterogeneidades que, se não levadas em conta, podem tornar pouco efetivas as políticas de combate ao trabalho infantil. Por exemplo, há desde trabalho assalariado na área urbana ao não-remunerado na produção agrícola familiar. As ocupações são especializadas para cada gênero; as meninas são maioria no emprego doméstico e os meninos se sobressaem no trabalho agrícola.

A variação regional da incidência do trabalho infantil no Brasil é bastante acentuada. A Tabela 2 apresenta a participação no mercado de trabalho de meninos e meninas de 10 a 15 anos de idade, separadamente. Esses números são provenientes do estudo de Cardoso e Souza (2003), em que foram utilizados dados do Censo de 2000 do IBGE.

A participação no mercado de trabalho é maior entre os meninos $(11,1 \%)$ do que entre as meninas $(5,4 \%)$ e, em ter- 
TABELA 2

Participação de Meninas e Meninos de 10 a 15 Anos de Idade no Trabalho Infantil e na Freqüência Escolar

Brasil - 2000

Em porcentagem

\begin{tabular}{lcc}
\hline População de 10 a 15 Anos de Idade & Total & Urbano \\
\hline Meninas & 5,4 & 4,1 \\
Trabalha (somente trabalha ou trabalha e vai à escola) & 4,4 & 3,3 \\
Não trabalha e não freqüenta a escola & & 9,7 \\
Meninos & 11,1 & 8,0 \\
Trabalha (somente trabalha ou trabalha e vai à escola) & 4,7 & 6,2 \\
Não trabalha e não freqüenta a escola & 4,0 & 23,6 \\
\hline
\end{tabular}

Fonte: Cardoso e Souza (2003).

mos proporcionais, a incidência do trabalho é maior nas áreas rurais do que nas áreas urbanas para os dois gêneros. Ademais, a proporção de meninos e meninas que não freqüentam escola e não trabalham é significativa no meio rural $(7,2 \%$ e $8,0 \%$, respectivamente).

TABELA 3

Maiores Incidências de Trabalho Infantil (1) em Áreas Urbanas, segundo Sexo e Estados Selecionados

Brasil - 2000

\begin{tabular}{lc}
\hline Sexo e Estados Selecionados & Área Urbana \\
\hline MENINOS & \\
Números Absolutos & 53.037 \\
São Paulo & 37.973 \\
Minas Gerais & 21.074 \\
Bahia & 17.702 \\
Paraná & 14.384 \\
Goiás & \\
Em porcentagem & 11,42 \\
Tocantins & 6,73 \\
Goiás & 5,92 \\
Mato Grosso & 5,43 \\
Mato Grosso do Sul & 5,32 \\
Minas Gerais & \\
MENINAS & \\
Números Absolutos & \\
São Paulo & 88.795 \\
Minas Gerais & 61.225 \\
Bahia & 40.763 \\
Paraná & 31.238 \\
Ceará & 26.295 \\
Em porcentagem & \\
Tocantins & 16,26 \\
Mato Grosso & 11,36 \\
Rondônia & 10,89 \\
Goiás & 10,69 \\
Maranhão & 9,83 \\
\hline Fonte: Cardso Souza & \\
\hline & \\
\hline & \\
& \\
&
\end{tabular}

Fonte: Cardoso e Souza (2003).

(1) De 10 a 15 anos de idade.
Os Estados de São Paulo, Minas Gerais e Bahia apresentam as maiores incidências de trabalho infantil urbano em números absolutos tanto para meninos quanto para meninas. Em termos relativos, o Centro-Oeste aparece em primeiro lugar (Tabelas 3 e 4). Quanto ao trabalho infantil

TABELA 4

Maiores Incidências de Trabalho Infantil (1) em Áreas Rurais, segundo Sexo e Estados Selecionados

Brasil - 2000

\begin{tabular}{lc}
\hline Sexo e Estados Selecionados & Área Rural \\
\hline MENINOS & \\
Números Absolutos & 27.100 \\
Bahia & 18.626 \\
Rio Grande do Sul & 15.828 \\
Minas Gerais & 13.728 \\
Pernambuco & 13.567 \\
Maranhão & \\
Em porcentagem & 19,65 \\
Rio Grande do Sul & 18,42 \\
Santa Catarina & 15,38 \\
Espírito Santo & 13,29 \\
Alagoas & 12,51 \\
Rondônia & \\
& \\
MENINAS & \\
Números Absolutos & \\
Bahia & 66.544 \\
Ceará & 44.856 \\
Maranhão & 42.628 \\
Minas Gerais & 41.584 \\
Pará & 37.585 \\
Em porcentagem & \\
Espírito Santo & 35,11 \\
Rondônia & 33,79 \\
Rio Grande do Sul & 31,81 \\
Paraíba & 31,40 \\
Piauí & 31,24 \\
\hline Fonte: Cardoso Souza & \\
\hline
\end{tabular}

Fonte: Cardoso e Souza (2003)

(1) De 10 a 15 anos de idade. 
rural, Rio Grande do Sul e Santa Catarina exibem taxas elevadas para ambos os sexos. Em números absolutos, o Estado da Bahia registra os números mais elevados.

Em síntese, existe uma variação significativa da incidência do trabalho infantil entre as regiões e os Estados brasileiros e em parte isso se deve à variação regional da pobreza e a outros aspectos regionais não diretamente associados a ela. A estrutura agrária local, o acesso à educação, a qualidade da educação oferecida, o funcionamento do mercado de trabalho local, as normas sociais locais, etc. são fatores determinantes do trabalho infantil que explicam a heterogeneidade regional.

\section{Formulação de Metas de Redução da Pobreza}

A formulação de políticas de redução de pobreza deve ter objetivos claros e estratégias de implementação que devem ser constantemente avaliadas e revistas e, para isso, a construção de indicadores sociais é fundamental. A seção anterior permite enfatizar três pontos importantes. Primeiro, a pobreza é um fenômeno multidimensional que envolve diferentes aspectos das condições socioeconômicas das pessoas. Uma política de redução da pobreza deve levar em conta os aspectos mais importantes e não apenas uma dimensão. Segundo, a construção de qualquer indicador envolve uma série de opções normativas e metodológicas que devem ser explicitadas. Terceiro, as várias dimensões da pobreza são bastante heterogêneas no Brasil, no que diz respeito à insuficiência de renda e ao trabalho infantil.

A fim de se formular uma política de redução da pobreza, é possível selecionar e construir um conjunto de indicadores sociais que serviriam tanto como metas como aferição e avaliação das políticas adotadas. Muitos indicadores já são elaborados por diversos institutos brasileiros e outros poderiam ser criados, dependendo das necessidades e dos objetivos. O importante é criar um conjunto de metas de redução de pobreza que se torne políticas nacionais e locais consistentes. Obviamente os indicadores selecionados devem atender a alguns princípios que são aceitos e compartilhados.

Atkinson et al. (2002) propõem os seguintes princípios para a construção de indicadores de inclusão social na Comunidade Européia (ATKINSON et al., 2002, p. 190), os quais parecem ser uma boa lista para iluminar o debate brasileiro.

Para o conjunto dos indicadores, os autores estabelecem três princípios:
- o conjunto de indicadores deve ser balanceado pelas diferentes dimensões;

- os indicadores devem ser mutuamente consistentes e o peso de um indicador particular no conjunto deve respeitar alguma proporcionalidade;

- o conjunto de indicadores deve ser transparente e acessível a todos os cidadãos.

Os princípios para cada indicador em particular são: - um indicador deve representar a essência do problema e ter uma interpretação normativa clara e reconhecida por todos;

- deve ser robusto e estatisticamente válido;

- deve ser sensível para captar intervenções de políticas públicas, mas não sujeito à manipulação;

- deve ser mensurável e comparável entre as diferentes regiões e, na medida do possível, comparável com os padrões internacionais das Nações Unidas;

- deve ser suscetível de revisão;

- a mensuração de um indicador não deve impor muito custo sobre os cidadãos e os Estados.

Ademais, os autores recomendam uma estrutura em três níveis. O primeiro consiste em um número restrito de indicadores líderes amplos que reflitam aqueles elementos considerados mais importantes na exclusão social. O segundo consiste em indicadores que descrevam outras dimensões do problema e que sirvam de apoio aos indicadores líderes. O terceiro nível, por fim, consiste em indicadores considerados relevantes pelos Estados, regiões ou municípios que enfatizem aspectos regionais específicos e que ajudem a interpretar os indicadores dos níveis superiores.

Assim, seria possível pensar em uma política de combate à pobreza na qual os diversos aspectos do problema seriam refletidos nesse conjunto de indicadores. A política social estabeleceria metas abertas e conhecidas por todos a serem perseguidas. Tais metas seriam diferenciadas por esses três níveis e refletiriam as especificidades e heterogeneidades regionais. Essa política seria periodicamente avaliada num processo público.

É importante enfatizar aqui o papel das avaliações. Antes de julgar normativamente uma política, a avaliação busca analisar sua efetividade (ela alcança o resultado desejado?) e a sua eficiência (poderia se obter o mesmo resultado com menor custo?). Em outras palavras, a avaliação significa aprender com os próprios erros e acertos.

Por fim, a implementação de uma política de metas de redução de pobreza significa dispor de informações 
socioeconômicas das pessoas e regiões, obtidas pelas pesquisas por amostragem de domicílio, como as desenvolvidas pelo IBGE e Seade. Assim, é preciso fortalecer e ampliar a capacidade estatística dessas instituições, as quais já possuem larga experiência.

\section{CONSIDERAÇÕES FINAIS}

Sendo o crescimento com distribuição o principal alvo a ser atingido pela política econômica, propõe-se aqui uma política explícita de metas de redução de pobreza e sua constante avaliação. Para isso, seria preciso eleger e construir indicadores relevantes e reconhecidos por todos e sugerir alguns princípios que norteariam sua formulação.

Uma política de metas de redução de pobreza permite integração das políticas sociais com tratamentos locais. Para isso necessita-se do envolvimento de instituições públicas que estejam diretamente voltadas para tais objetivos. Além disso, e o mais importante, requer-se o envolvimento dos próprios cidadãos diretamente interessados, alvos de tais políticas. Afinal, quem mais sabe de suas condições de privação e como superá-las são os próprios indivíduos.

\section{NOTA}

1. Em números absolutos existem mais domicílios vivendo abaixo das linhas de indigência e pobreza nas áreas urbanas do que nas áreas rurais.

\section{REFERÊNCIAS BIBLIOGRÁFICAS}

ACEMOGLU, D.; JOHnSON, S.; ROBInSON, J.A. The Colonial Origins of Comparative Development: an Empirical Investigation. American Economic Review, v. 91, p. 1.369-1.401, dez. 2001.

ATKInSON, T.; CANTILlON, B.; MARLIER, E.; NOLAN, B. Social Indicators. The E.U. and Social Inclusion. Oxford: Oxford University Press, 2002. p. 240.

AZZONI, C.R.; SOUZA, A.P.; NOGUEIRA, V.A. Regional and demographic determinants of poverty in Brazil. São Paulo: USP, 2004. Mimeografado.

BRIDSALL, N.; LODOÑO, J.L. Asset inequality matters: an assessment of the World's Bank approach to poverty reduction. American Economic Review, v. 87, n. 2, p. 32-37, 1997.
CARDOSO, E.; SOUZA, A.P. The impact of cash transfers on child labor and school attendance in Brazil. São Paulo: USP, 2003. Mimeografado.

CLARKE, G.R.G. More evidence on income distribution and growth. Journal of Development Economics, v. 47, p. 403-27, ago. 1996.

DEININGER, K.; SQUIRE, L. New ways of looking at old issues: inequality and growth. Journal of Development Economics, v. 57, p. 259-287, dez. 1998.

FAVA, V.L. Urbanização, custo de vida e pobreza no Brasil. São Paulo: IPE/USP, 1984. p. 182.

FIELDS, G.S. Distribution and development. A new look at the developing world. Cambridge: MIT Press, 2001. 260p.

FORBES, K.J. A Reassessment of the Relationship Between Inequality and Growth. Cambridge: MIT, 1998. Mimeografado.

KALDOR, N. Alternative theories of distribution. Review of Economic Studies, v. 23, p. 83-100, 1956.

KUZNETS, S. Economic Growth and Income Inequality. American Economic Review, v. 45, n. 1, p. 1-28, mar. 1955.

LI, H.; H-F, ZOU. Income Inequality is not Harmful For Growth: Theory and Evidence. Review of Development Economics, v. 2, p. 318-334, mar. 1998.

MEIER, G.M.; STIGLITZ, J.E. (Ed.). Frontiers of Development Economics. The Future in Perspective. Washington: World Bank, 2001. 575p.

NERI, M.; FERREIRA, F.H.; LANJOW, P. A robust poverty profile for Brazil using multiple data sources. Revista Brasileira de Economia, v. 57, n. 2, p. 59-92, 2003.

PERSSON, T.; TABELLINI, G. Is Inequality Harmful to Growth? American Economic Review, v. 84, n. 3, p. 600-621, jun. 1994.

RAVAlliON, M. Poverty Comparisons. Chur, Switzerland: Harwood Academic Publishers, 1994.

ROCHA, S. A pobreza no Brasil. Rio de Janeiro: FGV, 2003.

Do consumo observado à linha de pobreza. Pesquisa e Planejamento Econômico, v. 27, n. 2, ago. 1997.

SEN, A. Development as Freedom. New York: Anchor Books, 2000. $366 \mathrm{p}$.

. Resources, Values and Development. Oxford: Basil Blackwell, 1984.

Poverty and Famines: An Essay on Entitlement and Deprivation. Oxford: Clarendon Press, 1981.

SOUZA, A.P. Aspectos do trabalho infantil no Brasil. Revista de Economia \& Relações Internacionais, v. 2, p. 113-121, jul. 2003.

André Portela Souza: Professor do Departamento de Economia da Universidade de São Paulo e Pesquisador da Fundação do Instituto de Pesquisas Econômicas da USP (aps@usp.br). 